\title{
Future costs in cost-effectiveness analysis: an empirical assessment
}

\author{
Marie Kruse • Jan Sørensen · Dorte Gyrd-Hansen
}

Received: 19 June 2009/Accepted: 14 September 2010/Published online: 28 September 2010

(c) The Author(s) 2010. This article is published with open access at Springerlink.com

\begin{abstract}
Aim The aim of this study was to assess the impact on the cost-effectiveness ratio of including measures of production and consumption following a health care or health promotion intervention that improves survival.

Data and methods We defined the net incremental consumption, or future costs, as the change in consumption minus change in production, while differentiating between health care and non-health care consumption. Based on 2005 register-based data for the entire Danish population, we estimated the average value of annual production and consumption for 1-year age groups. We computed the net consumption in the remaining expected lifetime and the net consumption per life year gained for different age groups. Results Age has a profound effect on the magnitude of net consumption. When including net incremental consumption
\end{abstract}

M. Kruse · J. Sørensen

Centre for Applied Health Services

Research and Technology Assessment,

University of Southern Denmark,

Odense, Denmark

M. Kruse $(\bowtie) \cdot$ D. Gyrd-Hansen

Institute of Public Health,

Health Economics Unit,

University of Southern Denmark,

Odense, Denmark

e-mail: mkru@cast.sdu.dk

\section{Kruse}

National Institute of Public Health,

University of Southern Denmark,

Odense, Denmark

D. Gyrd-Hansen

Danish Institute for Health Services Research,

Copenhagen, Denmark in the cost-effectiveness ratio of a health care or health promotion intervention, the relative cost-effectiveness changed up to $€ 21,000$ across age groups. The largest difference in the cost-effectiveness ratio was observed among the 30-year-olds where costs were reduced significantly due to significant future net contributions to society.

Conclusion This paper contains cost figures for use in cost-effectiveness analyses, when the societal perspective is adopted and future consumption and production effects are taken into account. The net consumption varies considerably with age. Inclusion of net incremental consumption in the cost-effectiveness analysis will markedly affect the relative cost-effectiveness of interventions targeted at different age groups. Omitting future cost from cost-effectiveness analysis may bias the ranking of health care interventions and favour interventions aimed at older age groups. We used Danish data for this assessment, and our results will therefore not represent true figures for other countries. We do, however, believe that the overall impact of including net production value in CEA will be similar in other countries that have similar transfers of income from the younger age groups to older age groups as well as publicly financed social and health care services.

Keywords Future costs - Cost-effectiveness analysis . Life years saved

JEL Classification $\quad$ C31 $\cdot$ D61 $\cdot$ I10

\section{Background}

For more than a decade, the field of economic evaluation in health care has been accompanied by a discussion about which cost components to include. Clearly, it is still an 
evolving discipline. The inclusion or exclusion of future non-medical costs (consumption net of production) is still being debated.

This topic was first raised in 1996 by the US Panel on Cost-Effectiveness in Health and Medicine [1], which came to play a major role by issuing a set of recommendations for cost-effectiveness analysis. The US Panel defined a reference case for cost-effectiveness analysis, which excluded production changes based on the argument that the loss of utility due to labour market changes when being ill would be captured by the QALY. Hence, inclusion of the productivity loss would be double counting. The US Panel also recommended that future unrelated health care costs should be included if it was found appropriate and feasible. Further, if unrelated health care costs were included, future non-health care consumption should also be included. The issue of future non-medical costs was subsequently addressed from a welfare theoretic perspective by a number of authors [2-4]. Among them, Meltzer [2] argued that changes in both future consumption (of non-medical goods) and production should be included in the cost-effectiveness ratio. However, his conclusion was challenged by Nyman [5], which launched another wave of discussion. We base our study on this more recent discussion on the inclusion of future consumption and production [5-10].

\section{Our position}

We assume a societal perspective of the cost-effectiveness analysis [11] and suggest that if we are operating in a society where there are no externalities such as transfer payments, a CEA based on QALYs that include the value of consumption (and the value of leisure time) should not include the cost of consumption, as there are no opportunity costs to other parties. Nor should the analysis include production gains, since there is no utility gain beyond the individual's consumption. However, in the real world, individuals may increase their consumption without contributing equivalently in terms of production value. Relatives may pay for the consumption or consumption may be financed via taxes. Alternatively, individuals may consume less than they earn, and instead contribute to society (via taxes), to family members' education - or to charity. Therefore, we argue that the figure that should be included in the numerator of the CUA is the net consumption (consumption minus production gain), since this figure may represent the opportunity cost to society if it is positive. If the net consumption is negative, it constitutes incurred utility beyond what may be captured by the QALY. If the QALY does not include utility of consumption (but does include the value of leisure time), gross production gain should figure in the numerator and thus would reflect the total utility generated.
Whether the QALY does capture utility of own consumption is a contentious issue, however. Lundin and Ramsberg [8] state that utility from consumption, and therefore production, is part of the QALY, as it seems inseparable from utility from health, exemplified by the utility of being crippled (health), which is very much related to wheelchair ownership (consumption). Gandjour [9] argues that Nyman's suggestion to exclude consumption during added years of life does not apply to consumption costs for the satisfaction of primary needs. He further states that it is not only the medical treatment that prolongs life, but also the satisfaction of primary needs such as food, shelter and clothing. In other words, Gandjour argues that resources for primary needs produce utility captured as additional survival time and hence in the denominator of the cost-utility ratio. Gandjour thus concludes that according to Nyman's principle, the costs of these resources should be included in a CEA. While Lundin and Ramsberg (2008) and Blomqvist [12] enter into the discussion of the characteristics of quality-of-life instruments, Gandjour's argument is more basic and very relevant when we are dealing with evaluation of life-extending interventions.

Hence, we argue that quality-of-life instruments include some elements of consumptions utility. At the same time, we suggest that this issue is of minor importance because the discussion of whether to include future costs or not is generally raised in connection with life-extending interventions. In that case, the relevant argument is the one presented very convincingly by Gandjour: that living per se necessarily incurs added future consumption costs, and therefore the value of life years necessarily includes the value of consumption (at least to a very significant degree).

Our viewpoint is therefore that since there are considerable transfer payments in most countries, we cannot assume that consumption and production value cancel each other out, and these two elements must therefore play a role in CEA. Further, we believe that there are good arguments for stating that the utility associated with life extension is captured by life years or QALYs, and therefore the best strategy is to avoid double counting of the value of consumption by subtracting the cost of consumption from the production value in the denominator. This is the theoretical basis for the empirical research conducted in this study.

\section{Data and methods}

The aim of this paper is to assess the empirical effect of including net future consumption in the cost-effectiveness computation, and the implications for decision-making within health care. We thus restrict our focus on the longterm consequences of health care and health promotion 
interventions that incur a gain in life expectancy. In particular when analysing health promotion initiatives, the impact of keeping people alive for a longer period of time is salient.

We focus our attention on incremental consumption and production following a health care intervention and provide population-based estimates of net incremental consumption. These terms are defined in the box.

\begin{tabular}{cc}
\hline Consumption & $\begin{array}{c}\text { Individual consumption of goods and services } \\
\text { and consumption of health care and other } \\
\text { public goods such as education and social } \\
\text { care } \\
\text { The change in consumption following a health } \\
\text { care intervention, e.g. increased consumption } \\
\text { following a gain in life years }\end{array}$ \\
Production & $\begin{array}{l}\text { Productive income or individual contribution to } \\
\text { society, measured by gross earnings }\end{array}$ \\
Incremental & $\begin{array}{l}\text { The change in production following a health } \\
\text { production }\end{array}$ \\
& $\begin{array}{l}\text { care intervention, e.g. an increase in } \\
\text { production due to more years in the labour } \\
\text { market }\end{array}$ \\
Net incremental & $\begin{array}{l}\text { The difference between incremental } \\
\text { consumption }\end{array}$ \\
& $\begin{array}{l}\text { collowing a health care intervention. If the net } \\
\text { incremental consumption is positive, the } \\
\text { intervention renders an additional cost, while } \\
\text { if it is negative, it represents a net gain to } \\
\text { society }\end{array}$
\end{tabular}

It seems intuitively clear that net consumption varies with age, making age a central issue in including net incremental consumption in the cost-effectiveness analysis. Only a few authors have assessed the impact of including net incremental consumption. Meltzer et al. and Manns et al. $[13,14]$ analysed specific health care interventions and concluded that the difference between production and consumption varies considerably with age.

In addition, a Swedish $\mathrm{PhD}$ dissertation computed production and consumption by large age intervals, albeit to some extent based on top-down computations [15]. We assessed the variation in net incremental consumption according to age by means of cross-sectional, empirical data, covering the whole Danish population, on production and consumption at the individual level, and modelled these in a lifetime perspective. Our contribution is thus to estimate the impact of including future net consumption in a Northern European setting where transfer payments is an important tool for ensuring welfare. In such countries, one would expect that there is a significant difference in net contributions across age groups due to an institutionalised transfer of benefits across age groups.
Data

In the study, we used 2005 register data at the individual level for the entire Danish population aged 16 and older. For each individual, we obtained information on gross earnings, pension fund payments and taxable income from the National Income Register. From the Register on Social Security we obtained information on all social benefits, including national pensions, early retirement benefit, social welfare and targeted subsidies. For publicly financed health care consumption, we derived data from the National Patient Register for hospital costs and the Health Insurance Register for primary health care. In addition, we used the Pharmaceuticals Database for costs of prescription pharmaceuticals. We merged all data on consumption and production with the Population Register in order to achieve information on age and number of household members for all individuals.

\section{Methods}

For each individual, we defined their contribution to production as their gross labour market income, including the share of earnings used for payment into pension funds. Thus, the production value for a given individual translates into their own income available for consumption, plus their saving for consumption in older ages (pension fund payments), plus their contribution to the utility of others (family and society via taxes).

Decomposing gross income allows us to estimate how much income is available for the individuals' consumption at a given point in time. Figure 1 displays the information required to estimate the approximate level of consumption for each individual. The shaded boxes comprise the measures that are included in the analysis: production and consumption.

Children and other individuals without a labour market income (e.g. individuals living from social welfare benefits) were assumed to have zero production. For individuals older than pension age (65 years of age), we subtracted an estimated benefit from private pension funds from production, as information on pension benefits could not be isolated.

Non-health care consumption was estimated by means of the resources available for non-health care consumption, i.e. the net disposable income. This includes labour market income net of taxes and savings, plus public subsidies and payments from pension funds. We did not have access to information on taxes paid; therefore, tax payments were computed using applicable tax rates and rebates and subtracted from taxable income. Note that we are not using transfer payments as a measure of cost per se, but as an indicator of the individuals' ability to consume. 


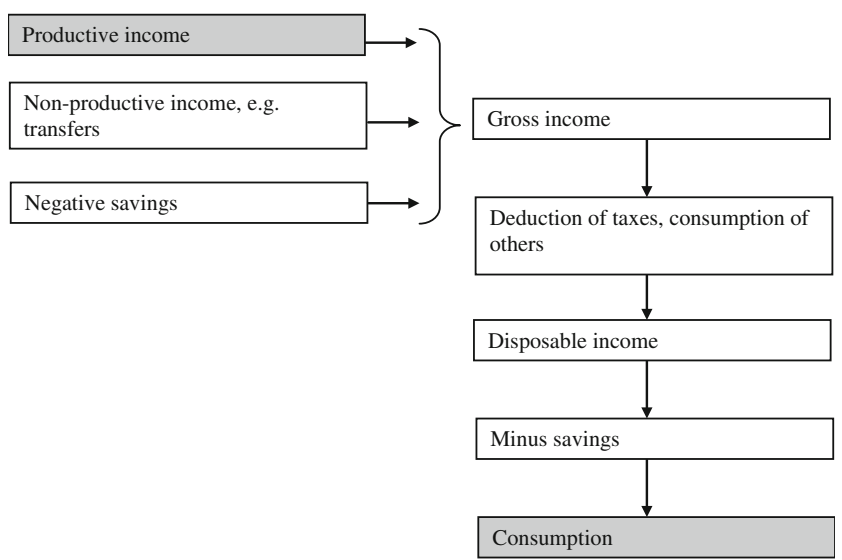

Fig. 1 Cost components, individual perspective

These figures were aggregated to household level and divided by the number of household members, assuming that all household members consume equal amounts. As an example, the non-health care consumption in a household consisting of two adults and three children (with no income) was computed as the sum of disposable income from the two adults, divided by five. This figure then constituted the nonhealth care consumption of each household member. Individual non-health care consumption for ages $0-18$ was assumed constant and equal to the average child consumption computed as parent's non-health care consumption figures divided by household members.

For consumption of public services other than health care, e.g. schools and nursing homes, we applied agespecific figures achieved by means of a top-down assessment of costs of education, day-care, care for the elderly, public transport etc. Any own payments for public services, e.g. for child day-care institutions, were included in individual non-health care consumption.

For savings, we assumed a constant savings rate of 10 per cent of disposable income during ages 25-60 and negative savings during ages $18-24$ and $67+$. This estimate was based on a survey among Danish pension fund members [16] and age-specific savings information from the US [17]. Consumption of real estate was distributed over the loan period, as instalments on a loan are included in nonhealth care consumption. Revenues from sale of real estate are not included in our estimate.

Finally, health care consumption was defined as costs of hospital services, primary health care services and prescription medicine, and was computed at the individual level. Hospital treatment in Denmark is funded through taxation and is free of direct charges. Each discharge was assigned a DRG-tariff, based on the national DRG system comprising average variable costs per diagnosis group. For outpatient and emergency contacts, a similar system was applied [18].
Most contacts in the primary health care sector are free of charge for the patient. The primary health care sector comprises general practitioners, practicing specialists, dentists and physiotherapists. For each contact, a claim is made to the health authorities based on a set of negotiated service tariffs. The National Health Insurance register covers all claims made from practitioners. The tariffs are in the present context interpreted as the average variable cost per service.

The Pharmaceuticals Database comprises purchases of all prescription medicine at an individual level, provided by primary care pharmacies. The costs of pharmaceuticals included in health care consumption equals the share of the price paid by public and private health insurance subsidies. Out-of-pocket payments (for medication, dentistry and physiotherapy) were not calculated, but implicitly included in non-health care consumption as these are goods paid for out of the monthly budget.

Analysis

The register-based information on production and consumption was derived for all individuals and averaged by 1 -year age groups in 2005. This cross-sectional data was used for describing production and consumption over a lifetime, thus keeping prices and wages at 2005-level.

We computed the net present value of net consumption in different ages, both in a lifetime perspective and per life year saved. Costs and life years were discounted at 3\% p.a. in the base case scenario and at 0 and $5 \%$ p.a. in a sensitivity analysis. The lifetime cost figures were computed with adjustment for survival, using the survival rates for the Danish population in 2007, and truncated at age 90. Thus, for the lifetime costs for, e.g. a 40-year-old person, the costs during ages 40-90 are adjusted for the number of people surviving to age 90 as well as for the time preference for consumption in the future.

Costs per life year gained were computed to enhance applicability for future cost-effectiveness analysis (CEA). Often CEA results are displayed as costs per life year gained (or QALY gained). We therefore computed the net present value of costs per life year gained. All costs are expressed in Euros, using the exchange rate $€ 1=7.5$ DKK.

\section{Results}

Figure 2 displays production and consumption (divided into health care consumption and non-health care consumption) for an average Danish citizen in 2005 by 1 year age groups.

From age 24 to age 62, production exceeds consumption. This is illustrated by the net consumption (shaded 
Fig. 2 Production, consumption and health care costs, Denmark 2005

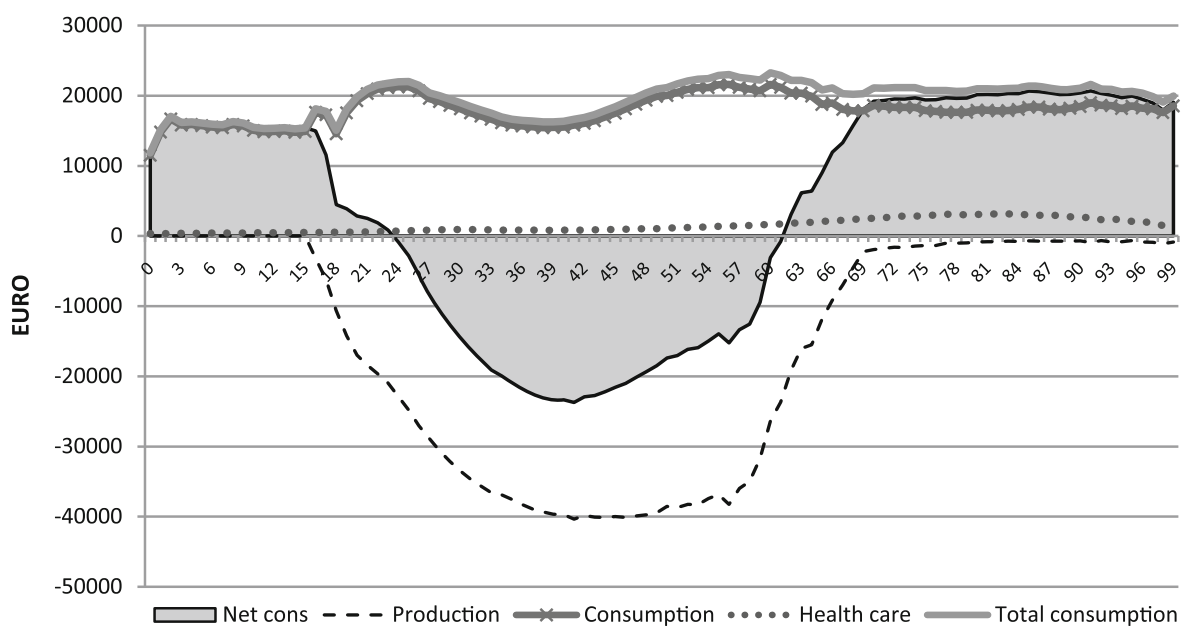

area) being negative. At older ages, consumption is subsidised. The average person aged 24-62 years is a net contributor, while the average person in the older age groups is a net beneficiary.

It appears from the figure that consumption of health care peaks around age 85 , while consumption of non-health care peaks around age 55. Bearing in mind that non-health care consumption is defined as household income divided by number of household members, this is not surprising, as the number of household members usually decreases at this stage, due to children leaving home, while household income remains high. Individual non-health care consumption without adjustment for household members peaks during the 40 s.

Table 1 presents the present value of lifetime consumption and production, based on the data in Fig. 2, but discounted to the time of a given health care or health promotion intervention. E.g. a health care intervention in a 35-year-old person would render a net present value of more than a quarter million Euros in a lifetime perspective, if he or she lives until the age of 90 .

When discounting costs and life years at $3 \%$ p.a., the change from net future contributor to net future beneficiary appears around the age of 50. When future consumption and production is not discounted (not shown), this change occurs in the early 40 s.

Interventions in older patients incur a positive net consumption as discounted consumption exceeds discounted production. In particular for old age pensioners with few earnings, the inclusion of net incremental consumption has a negative impact on the cost-effectiveness ratio of interventions targeting these age groups.

In Table 2, the lifetime figures are divided by the number of remaining life years to obtain the net incremental consumption per added life year. These figures are applicable in a cost-effectiveness analysis, as they express the cost per life year gained, and can be used in the incremental cost-effectiveness ratio (ICER). Life years are adjusted for survival and discounted by the same discount factor as net incremental consumption. To illustrate the impact of the discount factor, results for different discount rates are presented.

Application of these figures can be illustrated by the following example of inclusion of net incremental consumption in the cost-effectiveness analysis of a life-saving health care intervention (e.g. bypass surgery). The surgery has a (hypothetical) ICER of $€ 15,000$ per life year gained for all age groups compared to medical management, when net incremental consumption is not included. Inclusion of net incremental consumption (and applying a discount rate of $3 \%$ p.a.) would produce an ICER of $€ 24,300$ per life year gained for the 65-year-olds, while the cost-effectiveness of saving the life of a 40-year-old would be as low as $€ 8,800$.

\section{Discussion}

In this study, we have illustrated the impact on CEA ratios of including net incremental consumption, and examined the magnitude of net consumption for different age groups in the Danish population. It is obvious that including net incremental consumption has a major impact on the costeffectiveness ratio and that this impact differs between age groups and between interventions. Thus, inclusion of net incremental consumption renders a cost difference of $€ 21,000$ between the age group contributing the most and the age group benefiting the most.

In their 1995 review of costs per life year saved for live saving interventions, Tengs et al. [19] found that the median cost per life year saved for any health care intervention was $\$ 42,000$, equal to about $€ 37,000$ using 2005 prices and exchange rates. Given this level of cost per life years, a maximum difference of more than $€ 21,000$ across 
Table 1 Discounted production and consumption, EURO

\begin{tabular}{lcllc}
\hline $\begin{array}{l}\text { Age at } \\
\text { intervention }\end{array}$ & Production & $\begin{array}{l}\text { Non-health } \\
\text { care } \\
\text { consumption }\end{array}$ & $\begin{array}{l}\text { Health care } \\
\text { consumption }\end{array}$ & $\begin{array}{l}\text { Net present } \\
\text { value of net } \\
\text { consumption }\end{array}$ \\
\hline 0 & 460,421 & 517,747 & 23,021 & 80,348 \\
5 & 519,637 & 520,759 & 24,330 & 25,452 \\
10 & 602,701 & 518,205 & 26,067 & $-58,429$ \\
15 & 699,068 & 518,551 & 27,803 & $-152,714$ \\
20 & 802,028 & 521,217 & 31,054 & $-249,757$ \\
25 & 824,118 & 493,098 & 32,720 & $-298,300$ \\
30 & 801,178 & 464,148 & 33,533 & $-303,497$ \\
35 & 737,655 & 445,924 & 34,199 & $-257,532$ \\
40 & 646,764 & 433,846 & 35,372 & $-177,547$ \\
45 & 535,951 & 418,417 & 36,622 & $-80,912$ \\
50 & 410,263 & 388,862 & 37,646 & 16,246 \\
55 & 274,646 & 346,745 & 38,049 & 110,148 \\
60 & 130,242 & 297,663 & 37,610 & 205,032 \\
65 & 44,092 & 213,050 & 35,943 & 204,901 \\
70 & 14,358 & 206,856 & 32,567 & 225,065 \\
75 & 9,053 & 166,955 & 27,605 & 185,506 \\
80 & 5,828 & 133,245 & 21,611 & 149,027 \\
85 & 4,235 & 102,628 & 15,376 & 113,769 \\
\hline
\end{tabular}

These figures are not adjusted for survival. The discount rate is $3 \%$ p.a

Table 2 Net incremental consumption per gained life year, adjusted for survival, EURO

\begin{tabular}{lccl}
\hline $\begin{array}{l}\text { Age at } \\
\text { intervention }\end{array}$ & $\begin{array}{l}\text { Expected net } \\
\text { consumption per } \\
\text { added life year, } \\
\text { discounted } \\
\text { at 3\% p.a. }\end{array}$ & $\begin{array}{l}\text { Expected net } \\
\text { consumption per } \\
\text { added life year, } \\
\text { discounted } \\
\text { at 5\% p.a. }\end{array}$ & $\begin{array}{l}\text { Expected net } \\
\text { consumption per } \\
\text { added life year, } \\
\text { not discounted }\end{array}$ \\
\hline 0 & 2,469 & 5,735 & -484 \\
5 & 789 & 3,757 & $-1,233$ \\
10 & $-1,830$ & 310 & $-2,196$ \\
15 & $-4,840$ & $-3,964$ & $-3,240$ \\
20 & $-8,029$ & $-9,175$ & $-3,597$ \\
25 & $-9,751$ & $-12,234$ & $-3,941$ \\
30 & $-10,118$ & $-13,540$ & $-3,658$ \\
35 & $-8,788$ & $-12,483$ & $-2,604$ \\
40 & $-6,228$ & $-9,675$ & -966 \\
45 & $-2,934$ & $-5,777$ & 1,040 \\
50 & 613 & $-1,459$ & 3,193 \\
55 & 4,362 & 3,214 & 5,475 \\
60 & 8,612 & 8,703 & 8,034 \\
65 & 9,258 & 9,898 & 8,064 \\
70 & 11,148 & 12,134 & 9,542 \\
75 & 10,343 & 11,188 & 9,003 \\
80 & 9,725 & 10,425 & 8,641 \\
85 & 9,252 & 9,777 & 8,450 \\
\hline
\end{tabular}

The same discount rate was used for costs and life years age groups constitutes a significant relative change in costeffectiveness ratio estimates.

The illustration of net consumption over a lifetime shows that health care consumption increases with age. This is not surprising as the prevalence of most diseases increase with age. It follows that most health care interventions target individuals in older ages. On the other hand, health promotion interventions are not confined to any age group and could, in fact, be concentrated in younger age groups. In contrast, we observe that non-health care consumption tends to fall in older ages, which is probably a joint result of budget constraints as well as physical and psychological restrictions. In Denmark, the tax level is relatively high compared to other countries, and authorities provide substantial subsidies for people outside the labour market, notably pensioners. In countries where this is not the case, the drop in consumption around pension age is likely to be more distinct.

The recognition that inclusion of net consumption in the cost-effectiveness computation significantly alters the results of the cost-effectiveness analysis has been made by other authors [13, 14]. Meltzer et al. [13] analysed the impact of including net consumption in the analysis of cost-effectiveness of intensive therapy of young diabetics, using figures for net consumption that are at level with our findings. E.g. the net consumption in age group 22-34 was $-\$ 11,069$, equal to about $-€ 8,000$. Their overall finding was that for patients with an average age of 22, inclusion of net consumption decreased the cost-effectiveness ratio from $\$ 22,600$ to $\$ 9,600$ per quality-adjusted life year [13], equal to a difference of about $€ 9,500$. This estimate is very similar to the results presented in the present paper.

The inclusion of net incremental consumption could potentially affect the ordering of cost-effectiveness of interventions, if one intervention is aimed at younger and the other at older individuals. Also, prioritisation between health care and health promoting interventions could change. In the choice between interventions, the balance between a health-related quality-of-life-improving intervention and a length of life-improving intervention could change as a consequence of including net incremental consumption. It is likely that the cost of an intervention that increases patient's length of life, changes more markedly as a result of including future net consumption, than does the cost of an intervention that primarily improves patient's health-related quality of life, because a gain in life years induces added production and consumption in the added lifetime. However, an increase in HRQoL could enhance productivity and thus production. Also, a HRQoL gain could cause an increase in non-health care consumption, due to the improved possibility of consuming (travelling, restaurants etc.) following a health gain. Therefore, a HRQoL improving intervention also affects future net 
consumption, although the magnitude of this impact is more uncertain.

The empirical assessment of net incremental consumption was based on very detailed information on every individual in the Danish population. However, it was necessary to make a number of assumptions. The figures on production and information on health care consumption are retrieved directly from registers, and present as such quite powerful estimates of true average production and health care consumption. However, non-health care consumption at individual level had to be estimated based on a number of assumptions. We assumed certain simplifications of the tax rates in order to operationalise taxes. We based our assumptions on cross-sectional data, thus ignoring cohort effects such as increasing wealth and life expectancy in younger generations. We also assumed a constant savings rate during productive ages, that the revenue from sale of real estate can be ignored, and that all household members consume to the same extent. Perhaps the latter assumption is the most problematic. Intrahousehold distribution of non-health care consumption cannot be assessed through registers. Intuitively, it is clear that consumption of food increases with age, while consumption of other goods, such as clothes, may decrease with decreasing growth rate. From the figure, it appears that non-health care consumption during childhood is rather high, which also relates to the high costs of education and day-care institutions.

We tested the assumption of individual non-health care consumption being equal for all members of a household in a sensitivity analysis, where we applied the OECD set of household equivalents [20], according to which a child equals 0.5 adult (results not shown). Overall, this did not alter results significantly, aside from a small increase in the consumption of parents and consequently a small decrease in the net contribution during productive ages.

Another assumption relates to the computation of production gains. This is based on the human capital approach, according to which, an individual leaving the labour market at age 50 incurs a production loss equal to the discounted value of their labour market production for the remainder of their productive life (about 15 years). The human capital approach has been criticised as irrelevant in the presence of unemployment [21]. Instead, these authors proposed the friction cost approach which was rejected, however, as not being in accordance with economic theory [22]. Most importantly, the friction cost approach assumes that the opportunity cost for another employee to be hired equals zero.

In addition, in our estimation of production gains, nonlabour market production, such as household production, was not considered. Hence, the estimated production gains due to life extension will be underestimated to some extent.
Discounting future costs and effects reflects that individuals prefer consumption in the present to consumption in the future. In the analysis, we discounted costs and effects at $3 \%$ p.a. In a sensitivity analyses, we applied discount rates of 0 and $5 \%$, respectively, reflecting different preferences for costs and effects in the future. While it remains unlikely that individuals' time preferences do not change over time [23], albeit differently for costs and effects, we chose to maintain a fixed discount rate for simplicity reasons. In a possible application in an economic evaluation, however, the issue of varying discount rates should be considered.

The data for the empirical assessment were crosssectional, derived for 2005 for all age groups. Therefore, using the results as lifetime cost figures necessitates the assumption that no major deviations from 2005 conditions occur. Notably, the unemployment rate was historically low in 2005. Higher unemployment rates would render lifetime production and consumption lower. We assessed 2000 data in order to explore data for a year with higher unemployment rates, and found a similar pattern albeit with slightly smaller earnings, adjusted for inflation (results not shown).

It should also be noted that the analysis does not take into account any cohort effects. To the extent that production and consumption patterns vary considerably across cohorts, the presented cross-sectional analysis presented here will be imprecise.

\section{Conclusion}

This paper contains cost figures for use in cost-effectiveness analyses, when the societal perspective is adopted and future consumption and production effects are taken into account. We found that age has a profound effect on the magnitude of net consumption. Inclusion of net incremental consumption incurs a maximum change in the relative cost-effectiveness of more than $€ 21,000$ across age groups, when costs and effects are discounted with $3 \%$ p.a. The largest difference in the CEA ratio is observed among the 30-year-olds where the CEA ratio is reduced significantly due to significant future net contributions to society. Inclusion of net incremental consumption in the costeffectiveness analysis will affect the relative cost-effectiveness of interventions targeted at different age groups. Omitting future cost from cost-effectiveness analysis may bias the ranking of health interventions and favouring interventions aimed at older age groups. We used Danish data for this assessment, and our results will therefore not represent true figures for other countries. We do, however, believe that the overall impact of including net production value in CEA will be similar in other countries that have a 
similar transfer of income from the younger age groups to older groups as well as publicly financed social and health care services.

Acknowledgments This study was partly funded by an unrestricted research grant from the Danish Heart Foundation (4-B166-A139322386F). In addition, MK and JS were partly supported by the Danish Strategic Research Program on Sustainable Energy under contract no 2104-06-0027. We are grateful to two anonymous referees for their useful comments to an earlier version of this paper.

Open Access This article is distributed under the terms of the Creative Commons Attribution Noncommercial License which permits any noncommercial use, distribution, and reproduction in any medium, provided the original author(s) and source are credited.

\section{References}

1. Luce, B.R., Manning Jr, W.G., Siegel, J.E., Lipscomb, J.: Estimating costs in cost-effectiveness analysis. In: Gold, M.R., Siegel, J.B., Russell, L.B., Weinstein, M.C. (eds.) Cost-effectiveness in health and medicine, pp. 176-213. Oxford University Press, New York (1996)

2. Meltzer, D.: Accounting for future costs in medical cost-effectiveness analysis. J. Health Econ. 16(1), 33-64 (1997)

3. Garber, A.M., Phelps, C.E.: Economic foundations of costeffectiveness analysis. J. Health Econ. 16(1), 1-31 (1997)

4. Bleichrodt, H., Quiggin, J.: Life-cycle preferences over consumption and health: When is cost-effectiveness analysis equivalent to cost-benefit analysis? J. Health Econ. 18(6), 681-708 (1999)

5. Nyman, J.A.: Should the consumption of survivors be included as a cost in cost-utility analysis? Health Econ. 13(5), 417-427 (2004)

6. Garber, A.M., Phelps, C.E.: Future costs and the future of costeffectiveness analysis. J. Health Econ. 27(4), 819-821 (2008)

7. Meltzer, D.: Response to "Future costs and the future of costeffectiveness analysis". J. Health Econ. 27(4), 822-825 (2008)

8. Lundin, D., Ramsberg, J.: On survival consumption costs: A reply to Nyman. Health Econ. 17(2), 293-297 (2008)
9. Gandjour, A.: Consumption costs and earnings during added years of life - a reply to Nyman. Health Econ. 15(3), 315-317 (2006)

10. Gandjour, A.: Survivor costs in cost-effectiveness analysis. Ann. Intern. Med. 144(7), 534-535 (2006)

11. Gold, M.R., Siegel, J.E., Russell, L.B., Weinstein, M.C.: Costeffectiveness in Health and Medicine. Oxford University Press, New York (1996)

12. Blomqvist, A.: QALYs, standard gambles, and the expected budget constraint. J. Health Econ. 21(2), 181-195 (2002)

13. Meltzer, D., Egleston, B., Stoffel, D., Dasbach, E.: Effect of future costs on cost-effectiveness of medical interventions among young adults: The example of intensive therapy for type 1 diabetes mellitus. Med. Care 38(6), 679-685 (2000)

14. Manns, B., Meltzer, D., Taub, K., Donaldson, C.: Illustrating the impact of including future costs in economic evaluations: An application to end-stage renal disease care. Health Econ. 12(11), 949-958 (2003)

15. Ekman, M.: Studies in Health Economics-Modelling and Data Analysis of Costs and Survival [Stockholm School of Economics]. (2002)

16. Præstholm, S., Christensen, L., Jørgensen, S.A: [Pensions savings]. (2009), Online source

17. Attanasio, O.P.: Cohort analysis of saving behavior by US households. J. Hum. Resour. 33(3), 575-609 (1998)

18. The Danish Ministry of Health: Hospital Funding and Casemix. 1-89. Copenhagen (1999) Report

19. Tengs, T.O., Adams, M.E., Pliskin, J.S., Safran, D.G., Siegel, J.E., Weinstein, M.C., et al.: Five-hundred life-saving interventions and their cost-effectiveness. Risk Anal. 15(3), 369-390 (1995)

20. Forster M. Adjusting household incomes: Equivalence scales. OECD (2005) Available from: URL:http://www.oecd.org/ dataoecd/61/52/35411111.pdf

21. Koopmanschap, M.A., Rutten, F.F., van Ineveld, B.M., van Roijen, L.: The friction cost method for measuring indirect costs of disease. J. Health Econ. 14(2), 171-189 (1995)

22. Liljas, B.: How to calculate indirect costs in economic evaluations. Pharmacoeconomics 13(1 Pt 1), 1-7 (1998)

23. Bonneux, L., Birnie, E.: The discount rate in the economic evaluation of prevention: A thought experiment. J. Epidemiol. Community Health 55(2), 123-125 (2001) 